\title{
ANTIBIÓTICOS NAS FASES INICIAIS DA VIDA:UM PRECURSOR DA OBESIDADE INFANTIL
}

\author{
ANTIBIOTICS IN THE EARLY STAGES OF LIFE: A PRECURSOR TO CHILDHOOD \\ OBESITY
}

ANTIBIÓTICOS EN LAS FASES INICIALES DE LA VIDA: UN PRECURSOR DE LA OBESIDAD INFANTIL

Paulo André Duque Wanderley Filho ${ }^{1}$,Andrea Marques Vanderlei Ferreira ${ }^{2}$

\section{RESUMO}

Objetivo: integrar a produção científica sobre o uso de antibióticos nas fases iniciais da vida e sua relação com a obesidade infantil. Método: trata-se de uma revisão sistemática integrativa. Os descritores estruturados no DeCS, PediatricObesity, Antibiotic e Dysbiosis, foram utilizados nas varreduras das seguintes bases de busca: BVS, Wiley; ScienceDirect;MEDLINE; Biblioteca Virtual SciELO e LILACS. O período de coleta dos dados compreendeu os meses de abril e maio de 2018. Adotaram-se como critérios de inclusão: texto completo (free); publicado nos anos de 2014 a 2018; dos tipos artigo original e de revisão, artigo na imprensa, recurso, editorial, perspectiva e pesquisa transacional. Enquantoque os critérios de exclusão foram: livros; monografias; Trabalho de Conclusão de Curso; resumos, teses e dissertações; além de artigos que não contemplavam a relação entre o uso materno, no pré-natal, e/ou infantil de antibióticos com o desenvolvimento da obesidade infantil. Resultados: analisaram-se 126 trabalhos. Entretanto, obedeceram aos critérios de inclusão, apenas, 23 artigos científicos, sendo submetidos às seis etapas da revisão integrativa, entre os quais 14 eram estudos primários e dez eram de revisão. As categorias temáticas desenvolvidas a partir da análise dos trabalhos foram: 1 - Efeitos benéficos da amamentação na microbiota intestinal e perda do efeito metabólico protetor do leite materno devido ao uso de antibióticos; 2 - Disbiose da microbiota intestinal induzida pelo uso de antibióticos e sua influência no desenvolvimento da obesidade na infância; 3 - Exposições aos antibióticos nas fases iniciais da vida e suas relações com o sobrepeso e com a obesidade. Conclusão:os médicos devem atentar para as consequências, como a obesidade infantil, da prescrição de antibiótico nas fases iniciais da vida e considerar este problema como uma nova e séria razão para avaliar, criteriosamente, os riscos em longo prazo e benefícios em curto prazo da antibioticoterapia voltada para o público infantil.

\section{Descritores: Amamentação; Antibiótico; Disbiose; Obesidade Infantil.}

\footnotetext{
${ }^{1}$ Graduando em Medicina. Universidade Tiradentes de Alagoas/UNIT. Maceió (AL), Brasil. ${ }^{2}$ Doutor. Universidade Federal de Alagoas/UFAL. Maceió (AL), Brasil.
}

Rev. Port.Saúde e Sociedade.2019;4(1): 1028 - 1054. 
Objective: to integrate scientific production on the use of antibiotics in the early stages of life and its relation to childhood obesity. Method: it is a systematic integrative review. The structured descriptors in DeCS, Pediatric Obesity, Antibiotic and Dysbiosis, were used in the scans of the following search bases: BVS, Wiley; ScienceDirect; MEDLINE; virtual library SciELO and LILACS. The data collection period comprised the months of April and May 2018. Inclusion criteria were: full text (free); published in the years 2014 to 2018; original and review type articles, article in the press, feature, editorial, perspective and transactional research. While the exclusion criteria were: books; monographs; Final course work; abstracts, theses and dissertations; in addition to articles that did not contemplate the relationship between maternal, prenatal, and / or infantile use of antibiotics with the development of childhood obesity. Results: 126 papers were analyzed. However, only 23 scientific articles were included in the inclusion criteria, being submitted to the six stages of the integrative review, among which 14 were primary studies and ten were revision ones. The thematic categories developed from the analysis of the studies were: 1 - Beneficial effects of breastfeeding on the intestinal microbiota, and loss of the protective metabolic effect of breast milk due to the use of antibiotics; 2 Dysbiosis of the intestinal microbiota, induced by the use of antibiotics and its influence on the development of childhood obesity; 3 - Exposure to antibiotics in the early stages of life, and their relationship with overweight and obesity. Conclusion: physicians should pay attention to the consequences, such as childhood obesity, of antibiotic prescription in the early stages of life and consider this problem as a new and serious reason to carefully evaluate the long-term risks and short-term benefits of antibiotic therapy for children.

Descriptors: Breast Feeding; Anti-bacterial Agents; Dysbiosis; Pediatric Obesity.

\section{RESUMEN}

Objetivo: integrar la producción científica sobre el uso de antibióticos en las fases iniciales de la vida y su relación con la obesidad infantil. Método: se trata de una revisión sistemática integrativa. Los descriptores estructurados en el DeCS, Pediatricobesity, Antibiotic y Dysbiosis se utilizaron en las exploraciones de las siguientes bases de búsqueda: BVS, Wiley; ScienceDirect; MEDLINE; Biblioteca Virtual SciELO y LILACS. El período de recolección de los datos comprendió los meses de abril y mayo de 2018. Se adoptaron como criterios de inclusión: texto completo (free); publicado en los años de 2014 a 2018; de los tipos artículo original y de revisión, artículo en la prensa, el recurso, el editorial, la perspectiva y la investigación transaccional. Mientras que los criterios de exclusión fueron: libros; monografías; Trabajo de Conclusión de Curso; resúmenes, tesis y disertaciones; además de artículos que no contemplaban la relación entre el uso materno, en el prenatal, y/o infantil de antibióticos con el desarrollo de la obesidad infantil. Resultados: se analizaron 126 trabajos. Sin embargo, obedecieron a los criterios de inclusión, sólo, 23 artículos científicos, siendo sometidos a las seis etapas de la revisión integrativa, entre los cuales, 14 eran estudios primarios y diez eran de revisión. Las categorías temáticas desarrolladas a partir del análisis de los trabajos fueron: 1- Efectos benéficos de la lactancia materna en la microbiota intestinal y pérdida del efecto metabólico protector de la leche materna debido al uso de antibióticos; 2 Disbiosis de la microbiota intestinal inducida por el uso de antibióticos y su influencia en el desarrollo de la obesidad en la infancia; 3 - Exposiciones a los antibióticos en las fases iniciales de la vida y sus relaciones con el sobrepeso y la obesidad. Conclusión: los médicos deben atentar para las consecuencias, como la obesidad infantil, de la prescripción de antibiótico en las fases iniciales de la vida y considerar este problema como una nueva y seria razón para evaluar, cuidadosamente, los riesgos a largo plazo y beneficios a corto plazo de la antibioticoterapia orientada hacia el público infantil.

Rev. Port.Saúde e Sociedade.2019;4(1): 1028 - 1054. 


\section{Descriptores: \\ Pediátrica.

\section{INTRODUÇÃO}

A crescente prevalência da obesidade infantil é um dos maiores desafios enfrentados pelos profissionais médicos que cuidam de bebês e crianças. De acordo com os dados obtidos em um estudo sobre a prevalência da obesidade infantil e adulta nos Estados Unidos, no século XXI, foi feita a Pesquisa Nacional de Exame de Nutrição e Saúde 2011-2012. Segundo os dados dessa pesquisa, mais de uma em seis crianças e jovens, entre as idades de dois e 19 anos, é obesa, e mais de um em cada três está acima do peso. Crianças com sobrepeso e obesas correm um alto risco de se tornar adultos obesos. As consequências prejudiciais da obesidade para a saúde - aumento do risco de doenças metabólicas e cardiovasculares, problemas musculoesqueléticos e problemas psicossociais, como bullying e bulimia - podem se manifestar já na infância e se tornar mais prevalentes com o aumento da idade. ${ }^{1}$

Os antibióticos são medicamentos bastante administrados na infância. Apesar de reduzir expressivamente a morbidade e mortalidade de pacientes portadores de infecções bacterianas e possuir enormes vantagens em termos médicos, sociais e econômicos, o seu uso pode causar problemas indesejados entre os quais se destaca o desenvolvimento inadequado da flora bacteriana intestinal, favorecendo o desenvolvimento da obesidade. ${ }^{2}$

Observa-se que o uso excessivo de antibióticos de amplo espectro para condições responsivas a agentes de espectro estreito tem aumentado dramaticamente. $^{3}$

Um grande número de bactérias altamente diversificadas vive em simbiose com o corpo humano. Elas são chamadas, coletivamente, de microbiota. Os micróbios que habitam o corpo humano superam as células somáticas de um humano por um número estimado de dez vezes. ${ }^{4}$

Horas após o nascimento, os microrganismos da microbiota vaginal, fecal e/ou da pele da mãe e do ambiente são importantes colonizadores do intestino do bebê. Vários outros fatores, incluindo a prematuridade, a dieta infantil (leite materno ou fórmula), a higiene e o uso de antibióticos, exercem um impacto na composição da microbiota intestinal infantil. ${ }^{3}$

Rev. Port.Saúde e Sociedade.2019;4(1): 1028 - 1054. 
Estudos indicam a influência da microbiota intestinal na regulação e no desenvolvimento do metabolismo energético, no acúmulo de gordura e na suscetibilidade à adiposidade induzida pela dieta. Essa influência da microbiota intestinal desregulada é denominada obesidade induzida por disbiose. ${ }^{5}$

A colonização do intestino começa no período intrauterino e segue durante toda a vida da criança, sendo influenciada por uma variedade de fatores dietéticos e ambientais. Um fator observado na gênese da obesidade infantil é o papel do desequilíbrio precoce da flora intestinal, causado pela ação de fármacos bactericidas e/ou bacteriostáticos que podem transpor a barreira placentária ou atuar diretamente no organismo da criança, levando a um estado de disbiose intestinal. 6

Ao longo da última década, novas evidências de estudos em animais e humanos identificaram associações entre o desequilíbrio da microbiota intestinal, um estado denominado de disbiose, a desregulação do metabolismo do hospedeiro e o desenvolvimento da obesidade. ${ }^{7} \mathrm{O}$ uso de antibiótico materno durante o segundo e terceiro trimestres da gravidez foi associado a um aumento de $84 \%$ no risco de obesidade infantil aos sete anos de idade. ${ }^{8}$

Recentemente, uma série de novos problemas relacionados à disbiose da microbiota intestinal surgiu. Entre eles, a obesidade parece ser de particular relevância. A obesidade em crianças está aumentando em todo o mundo. 0 aumento do peso nos primeiros anos de vida tem demonstrado ser um risco significativo para a obesidade, de difícil tratamento na idade adulta, com o início do desenvolvimento de diabetes tipo 2 , doenças cardiovasculares e uma série de outras comorbidades graves. ${ }^{2}$

Sabe-se que a amamentação protege contra inúmeras infecções no início da vida, e a longa duração da amamentação também reduz o risco do sobrepeso em crianças. Os benefícios da amamentação estão relacionados à influência do leite materno no desenvolvimento inicial da microbiota intestinal, que é fortemente dependente da dieta do bebê. ${ }^{5}$

Em contraste com a microbiota intestinal madura de adultos saudáveis, que se mostra relativamente estável ao longo do tempo, a microbiota intestinal da criança só se estabelece e amadurece nos primeiros anos de vida. Dessa forma, a primeira infância parece representar uma janela etária crucial na prevenção das doenças relacionadas à disbiose. ${ }^{9}$

Rev. Port.Saúde e Sociedade.2019;4(1): 1028 - 1054. 
Nesse contexto, surgiu a pergunta norteadora deste estudo: "Qual a influência da exposição a antibióticos nos períodos pré-natal e pós-natal no desenvolvimento da obesidade infantil?".

Este estudo tem o objetivo de integrar a produção científica sobre o uso de antibióticos nas fases iniciais da vida e a sua relação com a obesidade infantil.

\section{MÉTODO}

Trata-se de uma revisão bibliográfica, do tipo sistemática integrativa, que seguiu as seguintes etapas (ver Figura 1): definição do tema; seleção da pergunta norteadora e escolha da estratégia de busca; descritores e bases de dados mais eficazes no levantamento das publicações; escolha dos critérios de inclusão e exclusão; identificação dos estudos pré-selecionados e selecionados por meio da leitura dos agentes indexadores das publicações, como resumos, palavras-chave e títulos, bem como a organização dos estudos pré-selecionados e a identificação dos estudos selecionados; categorização dos estudos selecionados, com a elaboração e o uso da matriz de síntese, além da análise das informações; a formação de uma biblioteca individual e a avaliação crítica dos estudos selecionados; análise, interpretação e discussão dos resultados ea apresentação da revisão em formato de artigo, o qual contempla as propostas para estudos futuros. ${ }^{10-11}$

Figura 1 - Detalhamento das etapas da Revisão Sistemática Integrativa.

\begin{tabular}{|c|c|c|}
\hline ETAPA & $\begin{array}{l}\text { TÓPICOS DE CADA } \\
\text { ETAPA }\end{array}$ & DETALHAMENTO DE CADA TÓPICO \\
\hline \multirow[t]{4}{*}{$1^{a}$} & Tema & $\begin{array}{l}\text { Antibióticos nas fases iniciais da vida: um } \\
\text { precursor da obesidade infantil. }\end{array}$ \\
\hline & Pergunta norteadora & $\begin{array}{l}\text { Qual a influência do desenvolvimento da } \\
\text { obesidade infantil após a exposição a antibióticos } \\
\text { nos períodos pré-natal e pós-natal? }\end{array}$ \\
\hline & Objetivo geral & $\begin{array}{l}\text { Integrar a produção científica sobre o uso de } \\
\text { antibióticos nas fases iniciais da vida e sua relação } \\
\text { com a obesidade infantil. }\end{array}$ \\
\hline & Estratégias de busca & $\begin{array}{l}\text { 1. Cruzamento de descritores por meio do } \\
\text { operador boleano AND; } \\
\text { 2. Uso de aspas nos politermos (descritor com } \\
\text { mais de um termo) para que a varredura de } \\
\text { artigos científicos contemplasse o termo exato; } \\
\text { 3. Uso de filtro do tipo data de publicação; } \\
\text { 4. Uso de descritores em inglês para ampliar o } \\
\text { número de artigos. }\end{array}$ \\
\hline
\end{tabular}

Rev. Port.Saúde e Sociedade.2019;4(1): 1028 - 1054. 


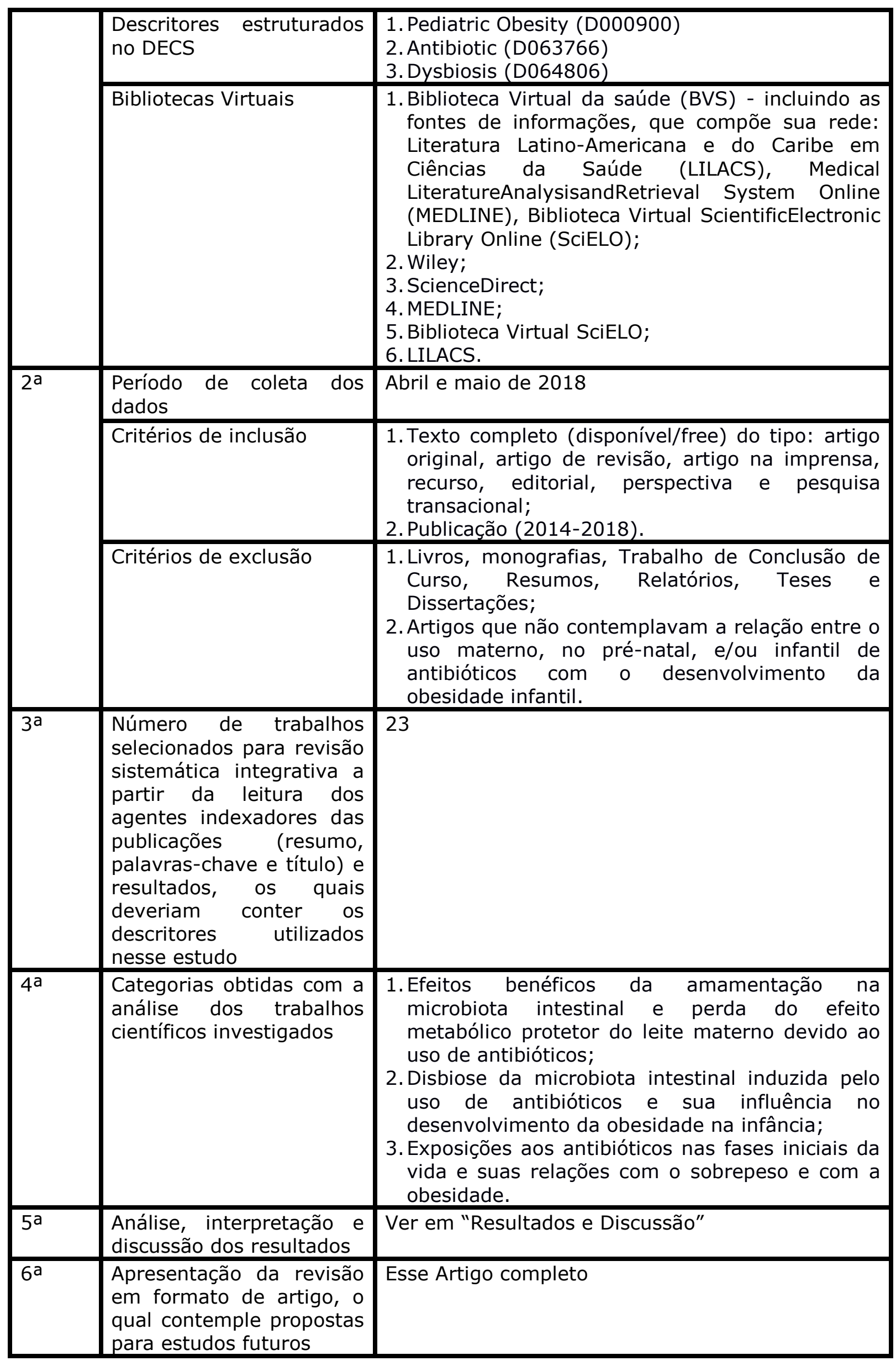

Rev. Port.Saúde e Sociedade.2019;4(1): 1028 - 1054. 
As características metodológicas dos trabalhos científicos analisados foram classificadas conforme o nível de evidência, segundo a proposta de Melnyk e Fineout-Overholt,12 em: I - Evidências provenientes da revisão sistemática ou metanálise de dados relevantes, ensaios clínicos randomizados controlados ou oriundas de diretrizes clínicas baseadas em revisões sistemáticas de ensaios clínicos randomizados controlados; II - Evidências derivadas de, pelo menos, um ensaio clínico randomizado controlado bem delineado; III - Evidências obtidas de ensaios clínicos bem delineados sem randomização; IV - Evidências provenientes de estudos de coorte e de caso-controle bem delineados; V - Evidências originárias da revisão sistemática de estudos descritivos e qualitativos; VI Evidências derivadas de um único estudo descritivo ou qualitativo e VII Evidências oriundas da opinião de autoridades e/ou relatórios de comitês de especialistas.

\section{RESULTADOS}

A figura2 corresponde ao quantitativo das varreduras realizadas nas principais bases de buscas.

Figura 2. Total of publications and texts available in the VHL, Wiley, ScienceDirect, Scielo, LILACS and MEDLINE using crossword of structured descriptors.

\begin{tabular}{|c|c|c|c|c|c|}
\hline $\begin{array}{l}\text { Cruzamento de } \\
\text { descritor }\end{array}$ & $\begin{array}{c}\text { Bases } \\
\text { de } \\
\text { dados }\end{array}$ & $\begin{array}{c}\text { Total de } \\
\text { publicaçõe } \\
\text { s sem o } \\
\text { filtro } \\
\text { "Assunto } \\
\text { principal" }\end{array}$ & $\begin{array}{c}\text { Textos } \\
\text { completos } \\
\text { disponívei } \\
\mathbf{s}\end{array}$ & $\begin{array}{c}\text { Textos } \\
\text { completos } \\
\text { disponívei } \\
\text { s após } \\
\text { aplicar os } \\
\text { filtros }\end{array}$ & $\begin{array}{c}\text { Textos } \\
\text { aproveitado } \\
\text { s na Revisão } \\
\text { Sistemática } \\
\text { Integrativa }\end{array}$ \\
\hline $\begin{array}{l}\text { "PediatricObesity } \\
\text { " andAntibiotic }\end{array}$ & $\begin{array}{c}\text { BVS } \\
\text { Scielo } \\
\text { LILACS } \\
\text { MEDLIN } \\
\text { E } \\
\text { Wiley } \\
\text { Science } \\
\text { Direct } \\
\end{array}$ & $\begin{array}{c}36 \\
0 \\
0 \\
16 \\
6.886 \\
109\end{array}$ & $\begin{array}{c}32 \\
0 \\
0 \\
7 \\
1.980 \\
61\end{array}$ & $\begin{array}{c}18 \\
0 \\
0 \\
7 \\
34 \\
4\end{array}$ & $\begin{array}{l}4 \\
0 \\
0 \\
3 \\
4 \\
3\end{array}$ \\
\hline
\end{tabular}

Rev. Port.Saúde e Sociedade.2019;4(1): 1028 - 1054. 


\begin{tabular}{|c|c|c|c|c|c|}
\hline $\begin{array}{l}\text { PediatricObesity" } \\
\text { andDysbiosis }\end{array}$ & $\begin{array}{c}\text { BVS } \\
\text { Scielo } \\
\text { LILACS } \\
\text { MEDLIN } \\
\text { E } \\
\text { Wiley } \\
\text { Science } \\
\text { Direct }\end{array}$ & $\begin{array}{c}11 \\
0 \\
0 \\
22 \\
376 \\
392\end{array}$ & $\begin{array}{c}10 \\
0 \\
0 \\
21 \\
341 \\
345\end{array}$ & $\begin{array}{c}4 \\
0 \\
0 \\
10 \\
9 \\
40\end{array}$ & $\begin{array}{l}2 \\
0 \\
0 \\
3 \\
3 \\
2\end{array}$ \\
\hline TOTAL & & 7.848 & 2.797 & 126 & 23 \\
\hline
\end{tabular}

Foram detectadas 7.848 publicações científicas nos bancos de dados, das quais 126 eram artigos científicos disponíveis após o uso dos filtros. Entretanto, obedeceram aos critérios de inclusão 23 artigos científicos (ver Figura 2), sendo submetidos às etapas da revisão integrativa (ver Figura 3). Entre eles, 14 eram estudos primários (originais) e dez eram de revisão (estudos secundários). Quanto ao ano de publicação, três estudos foram publicados no ano de 2018; cinco estudos foram publicados no ano de 2017; nove, no ano de 2016; seis, em 2015 e um, em 2014, o que evidencia a atualidade do tema. Todos os artigos estavam escritos em inglês. 
Figura3. Survey of scientific publications according to the inclusion criteria.

\begin{tabular}{|c|c|c|c|c|c|c|c|}
\hline No & CITAÇÃO & TEMA & ANO & $\begin{array}{c}\text { NÍVEL DE } \\
\text { EVIDÊNCIA }\end{array}$ & $\begin{array}{l}\text { OBJETIVO DO } \\
\text { ESTUDO }\end{array}$ & $\begin{array}{c}\text { CONCLUSÃO DO } \\
\text { ESTUDO }\end{array}$ & $\begin{array}{c}\text { CRUZAMENTO } \\
\text { DE } \\
\text { TERMINOLOGIA }\end{array}$ \\
\hline 1 & Scott et al. & $\begin{array}{l}\text { Administration } \\
\text { of Antibiotics } \\
\text { to Children } \\
\text { Before Age } 2 \\
\text { Years } \\
\text { Increases Risk } \\
\text { for Childhood } \\
\text { Obesity. }\end{array}$ & 2016 & IV & $\begin{array}{l}\text { Avaliar a associação } \\
\text { entre a exposição aos } \\
\text { antibióticos antes dos } \\
\text { dois anos de idade e } \\
\text { a obesidade na } \\
\text { infância. }\end{array}$ & $\begin{array}{l}\text { A administração de três } \\
\text { ou mais ciclos de } \\
\text { antibióticos antes que as } \\
\text { crianças atinjam uma } \\
\text { idade de } 2 \text { anos está } \\
\text { associada a um risco } \\
\text { aumentado de obesidade } \\
\text { na primeira infância. }\end{array}$ & $\begin{array}{l}\text { "Pediatric } \\
\text { Obesity" } \\
\text { Antibiotic }\end{array}$ \\
\hline 2 & Lemas et al. & $\begin{array}{l}\text { Exploring the } \\
\text { contribution of } \\
\text { maternal } \\
\text { antibiotics and } \\
\text { breastfeeding } \\
\text { to } \\
\text { development } \\
\text { of the infant } \\
\text { microbiome } \\
\text { and pediatric } \\
\text { obesity. }\end{array}$ & 2016 & $\mathrm{~V}$ & $\begin{array}{l}\text { Descrever os } \text { fatores } \\
\text { maternos, } \\
\text { práticas como } \\
\text { alimentação e uso de } \\
\text { antibióticos, como } \\
\text { mecanismos que } \\
\text { podem desequilibrar } \\
\text { a microbiota } \\
\text { intestinal do bebê e } \\
\text { elevar o risco de } \\
\text { obesidade infantil. } \\
\end{array}$ & $\begin{array}{l}\text { Os componentes } \\
\text { complexos do leite } \\
\text { humano têm muitos } \\
\text { benefícios nutricionais } \\
\text { para o bebê; no entanto, } \\
\text { o microbioma no leite } \\
\text { humano pode ser um } \\
\text { fator importante para } \\
\text { ajudar a regular o peso } \\
\text { do bebê. }\end{array}$ & $\begin{array}{l}\text { "Pediatric } \\
\text { Obesity" } \\
\text { Antibiotic }\end{array}$ \\
\hline 3 & Korpella et al. & $\begin{array}{l}\text { Association of } \\
\text { Early-Life } \\
\text { Antibiotic Use } \\
\text { and Protective } \\
\text { Effects of } \\
\text { Breastfeeding: } \\
\text { Role of the } \\
\text { Intestinal } \\
\text { Microbiota. }\end{array}$ & 2016 & IV & $\begin{array}{l}\text { Analisar se o uso } \\
\text { precoce } \\
\text { antibióticos }\end{array}$ & \begin{tabular}{lr}
\multicolumn{2}{c}{ O uso de antibióticos em } \\
uma criança durante a \\
amamentação & pode \\
enfraquecer os & efeitos \\
benéficos de & longa \\
duração & da \\
amamentação &
\end{tabular} & $\begin{array}{l}\text { "Pediatric } \\
\text { Obesity" } \\
\text { Antibiotic }\end{array}$ \\
\hline
\end{tabular}

Rev. Port.Saúde e Sociedade.2019;4(1): 1028 - 1054. 


\begin{tabular}{|c|c|c|c|c|c|c|c|}
\hline & & & & & $\begin{array}{lr}\text { associada } & \text { ao } \\
\text { desenvolvimento da } \\
\text { microbiota a longo } \\
\text { prazo. }\end{array}$ & & \\
\hline 4 & Turta, Rautava. & $\begin{array}{l}\text { Antibiotics, } \\
\text { obesity and } \\
\text { the link to } \\
\text { microbes - } \\
\text { what are we } \\
\text { doing to our } \\
\text { children? }\end{array}$ & 2016 & II & $\begin{array}{l}\text { Investigar } \\
\text { consequências } \\
\text { metabólicas } \\
\text { potencialmente } \\
\text { prejudiciais, a longo } \\
\text { prazo, da exposição } \\
\text { precoce r aos } \\
\text { antibióticos. }\end{array}$ & $\begin{array}{llr}\text { O uso prudente de } & \text { dé } \\
\text { antibióticos } & \text { é } \\
\text { fundamental não apenas } \\
\text { para reduzir a a } \\
\text { propagação } \\
\text { organismos resistentes a } \\
\text { antibióticos, r mas } \\
\text { também para minimizar } \\
\text { as consequências } \\
\text { metabólicas } \\
\text { potencialmente r } \\
\text { prejudiciais a longo } \\
\text { prazo da exposição } \\
\text { precoce aos antibióticos. }\end{array}$ & $\begin{array}{l}\text { "PediatricObesity" } \\
\text { andAntibiotic }\end{array}$ \\
\hline 5 & Magsariliet al. & $\begin{array}{l}\text { Making a Case } \\
\text { for Pediatric } \\
\text { Antimicrobial } \\
\text { Stewardship } \\
\text { Programs. }\end{array}$ & 2015 & II & $\begin{array}{lr}\text { Descrever } & \text { as } \\
\text { evidências } & \\
\text { atualmente } & \\
\text { disponíveis sobre o } \\
\text { manejo ro de } \\
\text { antimicrobianos, com } \\
\text { enfoque no público } \\
\text { pediátrico, no intuito } \\
\text { de evitar possíveis } \\
\text { efeitos colaterais } \\
\text { futuros que essa } \\
\text { família de fármacos } \\
\text { pode ocasionar }\end{array}$ & $\begin{array}{l}\text { Em geral, as } \\
\text { intervenções resultaram } \\
\text { em diminuição do uso de } \\
\text { antimicrobianos, redução } \\
\text { dos custos e menos } \\
\text { erros na prescrição de } \\
\text { antibióticos. }\end{array}$ & $\begin{array}{l}\text { "PediatricObesity" } \\
\text { andAntibiotic }\end{array}$ \\
\hline 6 & Schwartz et al. & $\begin{array}{l}\text { Antibiotic use } \\
\text { and childhood } \\
\text { body mass } \\
\text { index }\end{array}$ & 2016 & $\mathrm{I}$ & $\begin{array}{l}\text { Realizar um estudo } \\
\text { longitudinal, } \\
\text { grande escala, de } \\
\text { toda a faixa etária }\end{array}$ & $\begin{array}{l}\text { Os resultados sugerem } \\
\text { que o uso de antibióticos } \\
\text { influencia o ganho de } \\
\text { peso durante toda a }\end{array}$ & $\begin{array}{l}\text { "PediatricObesity" } \\
\text { andAntibiotic }\end{array}$ \\
\hline
\end{tabular}

Rev. Port.Saúde e Sociedade.2019;4(1): 1028 - 1054. 


\begin{tabular}{|c|c|c|c|c|c|c|c|}
\hline & & trajectory. & & & \begin{tabular}{|lrr} 
entre & \multicolumn{2}{r}{ crianças, } \\
observando se o uso \\
de antibióticos no \\
início da vida & tem \\
sido associação & com \\
ganho de r peso \\
durante & 0 \\
crescimento & e \\
desenvolvimento &
\end{tabular} & $\begin{array}{l}\text { infância e não apenas } \\
\text { durante os primeiros } \\
\text { anos de vida. }\end{array}$ & \\
\hline 7 & $\begin{array}{l}\text { Yallapragada, Nash, } \\
\text { Robinson. }\end{array}$ & $\begin{array}{l}\text { Early-Life } \\
\text { Exposure to } \\
\text { Antibiotics, } \\
\text { Alterations in } \\
\text { the Intestinal } \\
\text { Microbiome, } \\
\text { and Risk of } \\
\text { Metabolic } \\
\text { Disease in } \\
\text { Children and } \\
\text { Adults. } \\
\end{array}$ & 2015 & II & $\begin{array}{l}\text { Explorar a evolução } \\
\text { natural do microbiota } \\
\text { intestinal, desde o } \\
\text { período perinatal até } \\
\text { a infância, e o efeito } \\
\text { dos antibióticos sobre } \\
\text { a ecologia microbiana } \\
\text { fisiológica. }\end{array}$ &  & $\begin{array}{l}\text { "PediatricObesity" } \\
\text { andAntibiotic }\end{array}$ \\
\hline 8 & Moret al. & $\begin{array}{l}\text { Prenatal } \\
\text { exposure to } \\
\text { systemic } \\
\text { antibacterials } \\
\text { and } \\
\text { overweight } \\
\text { and obesity in } \\
\text { Danish } \\
\text { schoolchildren: } \\
\text { a prevalence } \\
\text { study. }\end{array}$ & 2015 & I & $\begin{array}{l}\text { Realizar um estudo } \\
\text { de prevalência entre } \\
\text { escolares } \\
\text { dinamarqueses com } \\
\text { idades entre 7-16 } \\
\text { anos, utilizando } \\
\text { dados de avaliações } \\
\text { antropométricas } \\
\text { escolares de rotina } \\
\text { realizadas durante } \\
2002-2013, \text { se } \\
\text { investigando } \\
\text { existe relação entre o } \\
\text { uso, precoce e/ou } \\
\text { irregular, de }\end{array}$ & $\begin{array}{l}\text { A exposição pré-natal a } \\
\text { antibióticos sistêmicos } \\
\text { está associada a um } \\
\text { aumento do risco de } \\
\text { sobrepeso e obesidade } \\
\text { na idade escolar, e essa } \\
\text { associação varia de } \\
\text { acordo com o peso ao } \\
\text { nascer. }\end{array}$ & $\begin{array}{l}\text { "PediatricObesity" } \\
\text { andAntibiotic }\end{array}$ \\
\hline
\end{tabular}

Rev. Port.Saúde e Sociedade.2019;4(1): 1028 - 1054. 


\begin{tabular}{|c|c|c|c|c|c|c|c|}
\hline & & & & & \begin{tabular}{|lrr}
$\begin{array}{l}\text { antibióticos } \\
\text { obesidade }\end{array}$ & com \\
infância. & & na \\
\end{tabular} & & \\
\hline 9 & Mueller et al. & $\begin{array}{l}\text { Prenatal } \\
\text { exposure to } \\
\text { antibiotics, } \\
\text { cesarean } \\
\text { section and } \\
\text { risk } \\
\text { childhood of } \\
\text { obesity. }\end{array}$ & 2016 & $\mathrm{I}$ & $\begin{array}{l}\text { Demonstrar que o } \\
\text { uso de antibióticos } \\
\text { durante a gestação } \\
\text { pode alterar a troca } \\
\text { normal da microbiota } \\
\text { materno-prole, } \\
\text { contribuindo para a } \\
\text { colonização } \\
\text { microbiana aberrante } \\
\text { do intestino infantil e } \\
\text { maior } \\
\text { susceptibilidade à } \\
\text { obesidade mais tarde } \\
\text { na vida }\end{array}$ & 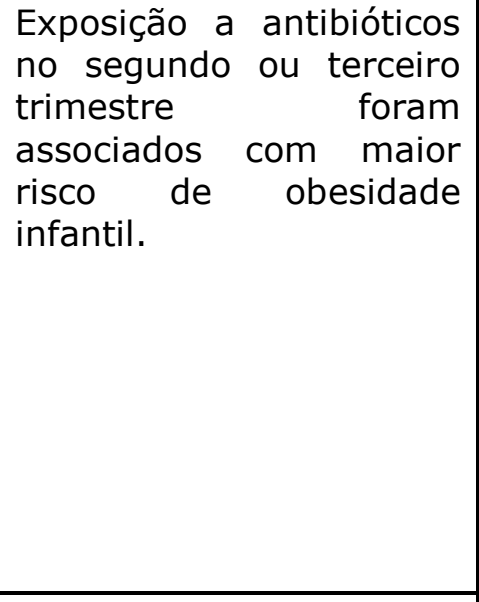 & $\begin{array}{l}\text { "PediatricObesity" } \\
\text { andAntibiotic }\end{array}$ \\
\hline 10 & Bailey et al. & $\begin{array}{l}\text { Association of } \\
\text { antibiotics in } \\
\text { infancy with } \\
\text { early } \\
\text { childhood } \\
\text { obesity. }\end{array}$ & 2014 & IV & $\begin{array}{l}\text { Avaliar o impacto de } \\
\text { antibióticos prescritos } \\
\text { na infância (idades } \\
\text { de } 0 \text { a } 23 \text { meses) } \\
\text { sobre a obesidade na } \\
\text { primeira infância } \\
\text { (idades de } 24 \text { a } 59 \\
\text { meses). }\end{array}$ & $\begin{array}{l}\text { A exposição repetida a } \\
\text { antibióticos de amplo } \\
\text { espectro entre } 0 \text { e } 23 \\
\text { meses está associada à } \\
\text { obesidade } \\
\text { precoce. }\end{array}$ & $\begin{array}{l}\text { "PediatricObesity" } \\
\text { andAntibiotic }\end{array}$ \\
\hline 11 & Shao et al. & $\begin{array}{l}\text { Antibiotic } \\
\text { Exposure in } \\
\text { Early Life } \\
\text { Increases Risk } \\
\text { of Childhood } \\
\text { Obesity: A } \\
\text { Systematic } \\
\text { Review and } \\
\text { Meta-Analysis }\end{array}$ & 2017 & V & 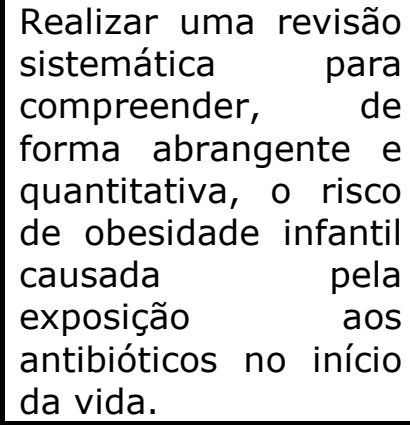 & $\begin{array}{l}\text { Foi observado que existiu } \\
\text { um relacionamento } \\
\text { dependente da dose de } \\
\text { antibiótico utilizada com } \\
\text { o desenvolvimento da } \\
\text { obesidade infantil. }\end{array}$ & $\begin{array}{l}\text { "PediatricObesity" } \\
\text { andAntibiotic }\end{array}$ \\
\hline
\end{tabular}

Rev. Port.Saúde e Sociedade.2019;4(1): 1028 - 1054. 


\begin{tabular}{|c|c|c|c|c|c|c|c|}
\hline 12 & Koleva,BridgmanKozyrskyj. & $\begin{array}{l}\text { The Infant Gut } \\
\text { Microbiome: } \\
\text { Evidence for } \\
\text { Obesity Risk } \\
\text { and Dietary } \\
\text { Intervention }\end{array}$ & 2015 & $\mathrm{~V}$ & \begin{tabular}{llr}
\multicolumn{3}{l}{ Resumir as pesquisas } \\
atuais sobre & a \\
associação & entre & a \\
microbiota & intestinal \\
infantil & e & a \\
obesidade. & &
\end{tabular} & $\begin{array}{l}\text { O abuso de antibióticos } \\
\text { pode causar a disbiose } \\
\text { da microbiota intestinal } \\
\text { infantil, e esse fator está } \\
\text { associado a } r \text { maior } \\
\text { chance do } r \text { ganho } \\
\text { excessivo de massa } \\
\text { corpórea no decorrer da } \\
\text { vida. }\end{array}$ & $\begin{array}{l}\text { "PediatricObesity" } \\
\text { andDysbiosis }\end{array}$ \\
\hline 13 & Forrest, Block, Bailey. & $\begin{array}{l}\text { Antibiotics, } \\
\text { infections, and } \\
\text { childhood } \\
\text { obesity. }\end{array}$ & 2017 & II & $\begin{array}{l}\text { Analisar uma possível } \\
\text { associação } \\
\text { exposição-resposta } \\
\text { entre o número de } \\
\text { episódios } \\
\text { tratamento de } \\
\text { antibióticos durante } \\
\text { os primeiros dois } \\
\text { anos de vida e } \\
\text { desenvolvimento de } \\
\text { obesidade na infância } \\
\text { tardia }\end{array}$ & $\begin{array}{l}\text { Foi identificada uma } \\
\text { associação entre a } \\
\text { frequência de uso de } \\
\text { antibióticos, com a } \\
\text { obesidade infantil., e } \\
\text { esse efeito foi mais } \\
\text { pronunciado para os de } \\
\text { antibióticos de amplo } \\
\text { espectro. }\end{array}$ & $\begin{array}{l}\text { "PediatricObesity" } \\
\text { andDysbiosis }\end{array}$ \\
\hline 14 & Lu, Ni. & $\begin{array}{l}\text { Gut microbiota } \\
\text { and the } \\
\text { development } \\
\text { of pediatric } \\
\text { diseases. }\end{array}$ & 2017 & IV & 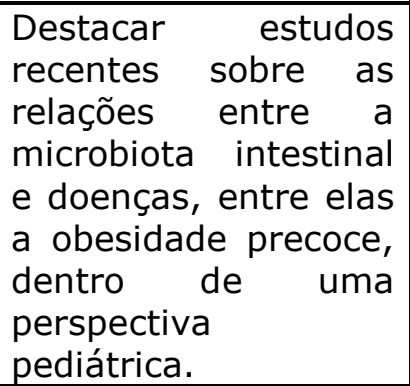 & $\begin{array}{l}\text { A disbiose desempenha } \\
\text { um papel importante em } \\
\text { várias doenças na } \\
\text { infância e na vida adulta: } \\
\text { obesidade e doenças } \\
\text { atópicas são alguns } \\
\text { exemplos. }\end{array}$ & $\begin{array}{l}\text { "PediatricObesity" } \\
\text { andDysbiosis }\end{array}$ \\
\hline 15 & Riva et al. & $\begin{array}{l}\text { Pediatric } \\
\text { obesity is } \\
\text { associated } \\
\text { with an altered } \\
\text { gut microbiota }\end{array}$ & 2017 & $\mathrm{~V}$ & $\begin{array}{lr}\text { Caracterizar } & a \\
\text { composição } & \text { da } \\
\text { microbiota intestinal } \\
\text { em crianças obesas } \\
\text { e com peso normal } \\
\end{array}$ & $\begin{array}{l}\text { Nossos resultados } \\
\text { sugerem que a disbiose } \\
\text { da microbiota intestinal } \\
\text { pode estar envolvida na } \\
\text { etiologia da obesidade }\end{array}$ & $\begin{array}{l}\text { "PediatricObesity" } \\
\text { andDysbiosis }\end{array}$ \\
\hline
\end{tabular}

Rev. Port.Saúde e Sociedade.2019;4(1): 1028 - 1054. 


\begin{tabular}{|c|c|c|c|c|c|c|c|}
\hline & & $\begin{array}{l}\text { and discordant } \\
\text { shifts in } \\
\text { Firmicutes } \\
\text { populations } \\
\end{array}$ & & & de 6 a 16 anos. & infantil. & \\
\hline 16 & Vangay et al. & $\begin{array}{l}\text { Antibiotics, } \\
\text { pediatric } \\
\text { dysbiosis, and } \\
\text { disease. }\end{array}$ & 2015 & IV & $\begin{array}{|lr|}\text { Sintetizar } & 0 \\
\text { conhecimento } & \text { atual } \\
\text { sobre a relação entre } \\
\text { antibióticos, disbiose } \\
\text { e doenças ligadas ao } \\
\text { metabolismo rr r e } \\
\text { propor } & \text { uma } \\
\text { conhecimentos } & \text { para } \\
\text { estudar a } & \text { disbiose } \\
\text { relacionada } & \text { a } \\
\text { antibióticos } & \text { em } \\
\text { crianças. } & \\
\end{array}$ & $\begin{array}{l}\text { Foi identificado que o } \\
\text { uso de antibióticos } \\
\text { durante a infância induz } \\
\text { desequilíbrios na } \\
\text { microbiota intestinal, } \\
\text { chamada disbiose. E que } \\
\text { as respostas da } \\
\text { microbiota intestinal aos } \\
\text { antibióticos possuem } \\
\text { potencial ligação com } \\
\text { desenvolvimento de } \\
\text { doenças, a exemplo da } \\
\text { obesidade. }\end{array}$ & $\begin{array}{l}\text { "PediatricObesity" } \\
\text { andDysbiosis }\end{array}$ \\
\hline 17 & García-Mantranet al. & $\begin{array}{l}\text { Perinatal } \\
\text { nutrition: how } \\
\text { to take care of } \\
\text { the gut } \\
\text { microbiota? }\end{array}$ & 2016 & $\mathrm{~V}$ & 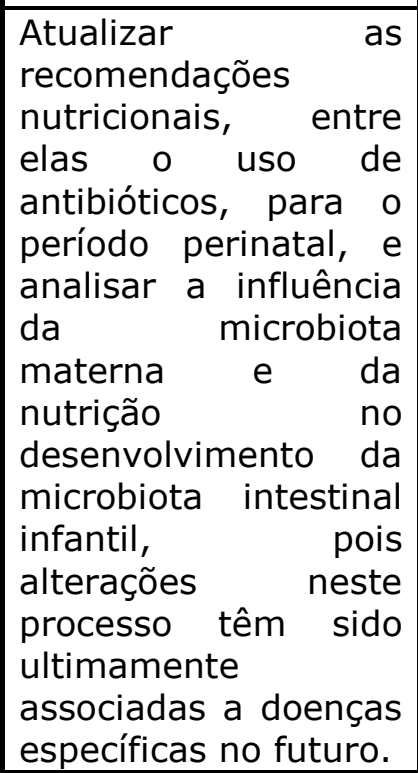 & $\begin{array}{l}\text { O estado nutricional } \\
\text { materno, o ambiente, a } \\
\text { dieta, o estilo de vida e } \\
\text { os micróbios estão } \\
\text { associados ao risco de } \\
\text { desenvolvimento de } \\
\text { doenças na infância, } \\
\text { como a obesidade, que } \\
\text { pode persistir na vida } \\
\text { adulta. }\end{array}$ & $\begin{array}{l}\text { "PediatricObesity" } \\
\text { andDysbiosis }\end{array}$ \\
\hline
\end{tabular}

Rev. Port.Saúde e Sociedade.2019;4(1): 1028 - 1054. 


\begin{tabular}{|c|c|c|c|c|c|c|c|}
\hline 18 & Moscetti, Pronk. & $\begin{array}{l}\text { Invisible } \\
\text { seams: } \\
\text { Preventing } \\
\text { childhood } \\
\text { obesity } \\
\text { through an } \\
\text { improved } \\
\text { obstetrics- } \\
\text { pediatrics care } \\
\text { continuum. }\end{array}$ & 2017 & $\mathrm{~V}$ & $\begin{array}{l}\text { Explorar fatores pré- } \\
\text { natais e da primeira } \\
\text { infância ras que } \\
\text { predispõem as ac as } \\
\text { crianças ao acúmulo } \\
\text { excessivo de gordura } \\
\text { e apresentar medidas } \\
\text { de prestação de } \\
\text { cuidados obstétricos } \\
\text { e pediátricos como } \\
\text { um meio de prevenir } \\
\text { a obesidade infantil. }\end{array}$ & $\begin{array}{l}\text { Uma prática clínica de } \\
\text { cuidados obstétricos- } \\
\text { pediátricos mais atenta } \\
\text { poderia abordar melhor, } \\
\text { e evitar, as origens } \\
\text { precoces da obesidade, } \\
\text { condição que estamos } \\
\text { verificando possuir } \\
\text { consequências ao longo } \\
\text { de toda a vida. }\end{array}$ & $\begin{array}{l}\text { "PediatricObesity" } \\
\text { andAntibiotic }\end{array}$ \\
\hline 19 & Fleming-Dutra et al. & $\begin{array}{l}\text { Prevalence of } \\
\text { inappropriate } \\
\text { antibiotic } \\
\text { prescriptions } \\
\text { among US } \\
\text { ambulatory } \\
\text { care visits, } \\
2010-2011 .\end{array}$ & 2016 & VI & $\begin{array}{lr}\text { Estimar as taxas de } \\
\text { prescrição } & \text { de } \\
\text { antibióticos r por } & \text { paciente em idade } \\
\text { ambulatorial por } \\
\text { idade e diagnóstico, e } \\
\text { as porções estimadas } \\
\text { de uso de antibióticos } \\
\text { que podem ser } \\
\text { inapropriadas em } \\
\text { adultos e crianças } \\
\text { nos Estados Unidos. }\end{array}$ & 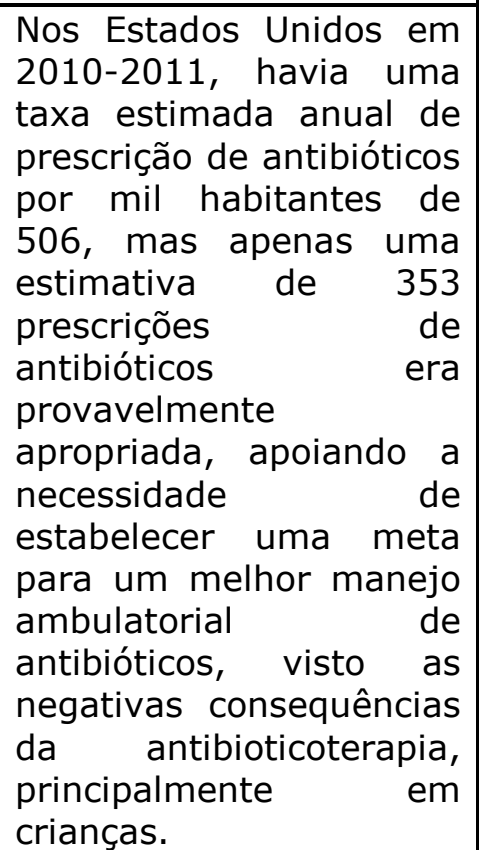 & $\begin{array}{l}\text { "PediatricObesity" } \\
\text { andAntibiotic }\end{array}$ \\
\hline 20 & Emmanouil, Raoult. & $\begin{array}{l}\text { Gut microbiota } \\
\text { modifications } \\
\text { and weight }\end{array}$ & 2018 & $\mathrm{~V}$ & $\begin{array}{lr}\text { Revisar os efeitos } & \text { da } \\
\text { administração } & \text { de } \\
\text { probióticos } & \mathrm{e}\end{array}$ & $\begin{array}{l}\text { A composição da } \\
\text { microbiota intestinal é } \\
\text { bastante sensível e tem }\end{array}$ & $\begin{array}{l}\text { "PediatricObesity" } \\
\text { andAntibiotic }\end{array}$ \\
\hline
\end{tabular}

Rev. Port.Saúde e Sociedade.2019;4(1): 1028 - 1054. 


\begin{tabular}{|c|c|c|c|c|c|c|c|}
\hline & & $\begin{array}{l}\text { gain in early } \\
\text { life. }\end{array}$ & & & $\begin{array}{l}\text { antibióticos no início } \\
\text { da vida sobre a } \\
\text { microbiota intestinal } \\
\text { e discutir seus efeitos } \\
\text { sobre o ganho de } \\
\text { peso }\end{array}$ & $\begin{array}{l}\text { mostrado um papel } \\
\text { fundamental na saúde } \\
\text { humana. Foi evidente } \\
\text { que a administração } \\
\text { precoce de antibióticos } \\
\text { pode ter implicações de } \\
\text { longo prazo, incluindo } \\
\text { perturbações da flora } \\
\text { intestinal e possíveis } \\
\text { condições crônicas, como } \\
\text { a obesidade. }\end{array}$ & \\
\hline 21 & Leong et al. & $\begin{array}{l}\text { Antibiotics, gut } \\
\text { microbiome } \\
\text { and obesity. }\end{array}$ & 2018 & $\mathrm{~V}$ & $\begin{array}{l}\text { Enfocar a associação } \\
\text { entre antibióticos e } \\
\text { obesidade, e o papel } \\
\text { da } \\
\text { intestinal microbiota } \\
\text { relação. }\end{array}$ & 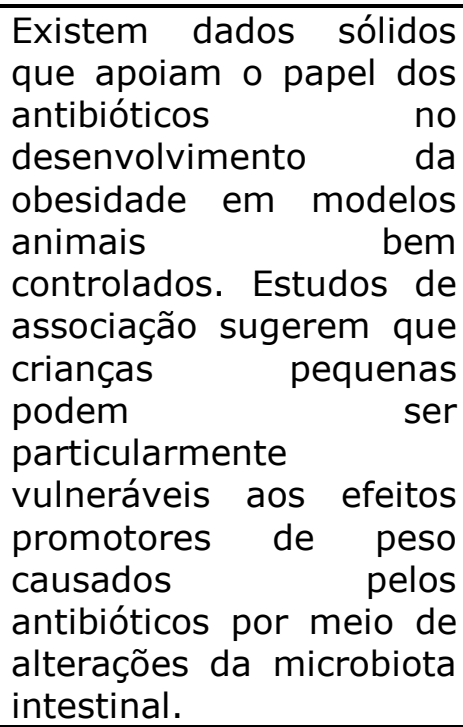 & $\begin{array}{l}\text { "PediatricObesity" } \\
\text { andAntibiotic }\end{array}$ \\
\hline 22 & López-Contrera et al. & $\begin{array}{l}\text { Composition of } \\
\text { gut microbiota } \\
\text { in obese and } \\
\text { normal-weight } \\
\text { Mexican } \\
\text { school-age } \\
\text { children and }\end{array}$ & 2018 & VI & $\begin{array}{l}\text { Comparar a } \\
\text { composição intestinal } \\
\text { microbiota inta } \\
\text { em crianças obesas e } \\
\text { com peso normal, e } \\
\text { associar os perfis da } \\
\text { microbiota intestinal }\end{array}$ & $\begin{array}{lr}\text { Não foram observadas } \\
\text { diferenças significativas } \\
\text { na abundância de filos } \\
\text { ou nas relações } \\
\text { Firmicutes/ Bacteroides } \\
\text { entre crianças com peso } \\
\text { normal e crianças }\end{array}$ & $\begin{array}{l}\text { "PediatricObesity" } \\
\text { andAntibiotic }\end{array}$ \\
\hline
\end{tabular}

Rev. Port.Saúde e Sociedade.2019;4(1): 1028 - 1054. 


\begin{tabular}{|c|c|c|c|c|c|c|c|}
\hline & & $\begin{array}{l}\text { its association } \\
\text { with metabolic } \\
\text { traits. }\end{array}$ & & & \begin{tabular}{ll}
\multicolumn{2}{|l|}{ com níveis séricos de } \\
aminoácidos & e \\
características & \\
metabólicas & \\
relacionadas & à \\
obesidade. &
\end{tabular} & $\begin{array}{l}\text { obesas. No entanto, a } \\
\text { abundância } \\
\text { BacteroidesEggerthii foi } \\
\text { significativamente maior } \\
\text { em crianças obesas e } \\
\begin{array}{l}\text { correlacionou-se } \\
\text { positivamente com o } \\
\text { percentual de gordura } \\
\text { corporal. }\end{array}\end{array}$ & \\
\hline 23 & Van Best et al. & $\begin{array}{l}\text { On the origin } \\
\text { of species: } \\
\text { factors the } \\
\text { shaping thent } \\
\text { establishment } \\
\text { of infant's gut } \\
\text { microbiota. }\end{array}$ & 2015 & $\mathrm{~V}$ & $\begin{array}{l}\text { Estudar a origem das } \\
\text { bactérias pioneiras e } \\
\text { os fatores } \\
\text { que influenciam o } \\
\text { desenvolvimento da } \\
\text { microbiota intestinal } \\
\text { em lactentes. }\end{array}$ & $\begin{array}{l}\text { A colonização de } \\
\text { bactérias essenciais } \\
\text { no intestino neonatal é } \\
\text { importante, uma vez que } \\
\text { sua falta } \\
\text { pode resultar em } \\
\text { aumento do risco de } \\
\text { doenças metabólicas ou } \\
\text { distúrbios, como } \\
\text { obesidade e/ou alergia. }\end{array}$ & $\begin{array}{l}\text { "PediatricObesity" } \\
\text { andAntibiotic }\end{array}$ \\
\hline
\end{tabular}

Rev. Port.Saúde e Sociedade.2019;4(1): 1028 - 1054. 
O site WordArt foi utilizado para se obter os termos mais frequentes nos resumos dos 23 artigos selecionados. Os termos mais prevalentes foram obesidade $(n=178)$, infância $(n=155)$, microbiota intestinal $(n=153)$, antibióticos $(n=151)$, disbiose $(n=56)$, sobrepeso $(n=34)$, leite materno $(n=28)$ e amamentação $(n=22)$.

\section{DISCUSSÃO}

Seguem, abaixo, as categorias temáticas elaboradas a partir da revisão sistemática integrativa.

\section{Efeitos benéficos da amamentação na microbiota intestinal e a perda do efeito metabólico protetor do leite materno devido ao uso de antibióticos}

As práticas exclusivas de aleitamento materno estão ligadas ao crescimento pós-natal saudável dos bebês por meio de uma ótima nutrição e da proteção da saúde. Esta evidência levou à recomendação de seis meses de amamentação exclusiva pela OMS. ${ }^{13}$

Sabe-se que a amamentação também protege contra inúmeras infecções no início da vida e que a amamentação prolongada também reduz o risco do sobrepeso em crianças. Os benefícios da amamentação, provavelmente, estão relacionados ao desenvolvimento inicial da microbiota intestinal, que é fortemente dependente da dieta do bebê. ${ }^{14}$

Após o nascimento, o determinante mais importante para a colonização do intestino infantil é a amamentação. O leite humano contém trilhões de bactérias vivas por litro e é uma fonte de estafilococos, estreptococos, bactérias do ácido láctico e, principalmente, Bifidobacterium, essenciais para o equilíbrio da microbiota intestinal. ${ }^{8}$ A colonização microbiana precoce tem um papel decisivo na saúde humana e alterações neste processo têm sido, ultimamente, associadas a doenças específicas no futuro, como a obesidade. ${ }^{13}$

O intestino do bebê é inicialmente colonizado por Proteobacteria, Bacteroides e Firmicutes, seguindo-se um aumento gradual de Bifidobacterium, produtores de ácidos graxos de cadeia curta que são contrários ao processo de obesidade, devido à introdução do leite materno. Aos seis meses de idade, os Bacteroides e Firmicutes dominam, enquanto as Proteobacteria e Bifidobacterium declinam gradualmente, o que pode ser atribuído ao período de desmame. Até o

Rev. Port.Saúde e Sociedade.2019;4(1): 1028 - 1054. 
final do primeiro ano de vida, o intestino do bebê é dominado por bactérias dos filos Bacteroides, Firmicutes e Bifidobacterium. O intestino saudável do bebê continua com mudanças dramáticas de composição ao longo dos dois primeiros anos de vida, antes de se tornar indistinguível de uma microbiota intestinal adulta, aos três anos de idade. ${ }^{3}$

O leite materno disponibiliza substratos que são utilizados como fontes de energia por espécies de bactérias, a exemplo das Bifidobacterium, que são abundantes no intestino do lactente, possuem ação probiótica e são essenciais para o bom funcionamento fisiológico do metabolismo energético infantil, pois produzem ácidos graxos de cadeia curta. ${ }^{5}$

As crianças que são amamentadas têm uma melhor regulação da saciedade e apetite do que crianças alimentadas com fórmulas, pois uma microflora saudável resulta em uma maior produção de ácidos graxos de cadeia curta, os quais estão associados ao aumento da saciedade e à diminuição da ingestão alimentar. ${ }^{6}$

Os ácidos graxos de cadeia curta favorecem a produção de alguns tipos de peptídeos (GLP-1, GLP-2 e PYY), que atuam no hipotálamo, ativando mecanismos responsáveis pelo aumento da saciedade e a diminuição da ingestão alimentar, melhorando a resposta glicêmica e insulinêmica e diminuindo a endotoxemia metabólica, comumente presente em obesos e portadores de DM2. ${ }^{15}$

Espécies de Bifidobacterium, com a redução da presença na microbiota intestinal de crianças sem amamentação e com tempo reduzido de amamentação ou que fizeram uso precoce de antibióticos, são conhecidas pela íntima relação com a saúde futura do ser. A presença adequada dessas bactérias na luz intestinal do lactente tem sido associada à proteção contra a obesidade induzida pela dieta e pelos efeitos metabólicos. Pensa-se que os efeitos metabólicos benéficos destas espécies surjam da melhoria da função de permeabilidade da barreira intestinal, que reduz a endotoxemia metabólica, responsável por aumentar a resistência à insulina e pelo desenvolvimento da obesidade. ${ }^{2}$

Um estudo de coorte retrospectivo, fez a associação entre a proteção da microbiota intestinal pelo leite materno e o uso de antibióticos por crianças e o índice de massa corporal por meio de uma coorte de 226 crianças saudáveis com idades entre dois e seis anos. ${ }^{2}$ A reunião desses dados permitiu uma análise

Rev. Port.Saúde e Sociedade.2019;4(1): 1028 - 1054. 
minuciosa e controlada das associações entre a duração da amamentação, a formação da microbiota intestinal e os indicadores de saúde.

Esse estudo deixou evidente que as crianças amamentadas têm uma melhor regulação da saciedade e do apetite que crianças alimentadas com fórmulas, e isso foi explicado pelas diferenças na microbiota intestinal das crianças com diferentes tipos de nutrição.

As crianças que apresentavam uma maior população de Bifidobacterium na composição da microbiota intestinal foram as que mais foram expostas ao leite materno, e foi esse grupo que apresentou um menor crescimento do índice de massa corporal. A obesidade está associada a um aumento da abundância de bactérias Firmucutes e a uma diminuição de Bifidobacterium. ${ }^{1}$

A nutrição irregular da criança, durante o período no qual o leite materno deveria ser a única fonte de nutrição, é capaz de aumentar o número de bactérias Firmicutes, responsáveis pela não produção de ácidos graxos de cadeia curta, e diminuir a população de Bifidobacterium. ${ }^{6}$

Foi observado que os efeitos protetores da amamentação contra as infecções e a obesidade foram enfraquecidos ou completamente eliminados pelo uso precoce de antibióticos, e que, além disso, a aparente impressão de uma microbiota protetora pela amamentação prolongada também foi eliminada pelo uso de antibióticos durante a amamentação. ${ }^{5}$

Estes resultados sugerem que os benefícios metabólicos da amamentação são transmitidos pelos efeitos benéficos do leite materno na microbiota intestinal, que pode ser estimulada positivamente pelo leite materno e negativamente, pelos antibióticos.

Dessa forma, entende-se que os benefícios metabólicos da amamentação como dieta principal e exclusiva até os seis meses de idade são ocasionados pelo crescimento e desenvolvimento de uma microbiota intestinal saudável e adequada para a idade, e que a amamentação também proporciona uma excelente proteção ao organismo contra a elevação do índice de massa corporal no decorrer da vida da criança.

\section{Disbiose da microbiota intestinal induzida pelo uso de antibióticos e a sua influência no desenvolvimento da obesidade na infância}

Rev. Port.Saúde e Sociedade.2019;4(1): 1028 - 1054. 
A microbiota intestinal humana é um ecossistema complexo e dinâmico, consistindo em centenas a milhares de distintas espécies bacterianas. Nas últimas décadas, o conhecimento sobre o papel da microbiota intestinal e o seu desenvolvimento, bem como sobre as interações hospedeiro-microrganismo na saúde e na doença humana, aumentou rapidamente devido ao avanço das tecnologias moleculares. A microbiota intestinal exerce um papel complexo no seu hospedeiro, proporcionando uma barreira contra patógenos invasores, utilizando componentes alimentares indigestos pelas enzimas do hospedeiro, produzindo metabólitos essenciais de ação sistêmica e modulando as respostas do sistema imunológico. ${ }^{9}$

A etiologia da obesidade é uma interação única entre a genética, os fatores socioeconômicos e as condições ambientais. Pesquisadores e profissionais estão, justamente, dando mais atenção às origens da obesidade precoce e demonstrando os seus papéis importantes para a disbiose da microbiota intestinal no desenvolvimento dessa condição. ${ }^{14}$

Até recentemente, acreditava-se que o feto e os ambientes intrauterinos eram estéreis e, assim, que o desenvolvimento da microbiota intestinal começava após o nascimento, por meio do canal vaginal ou da cesárea, no contato com a microbiota da pele. No entanto, estudos encontraram evidências de micróbios no líquido amniótico, no sangue do cordão umbilical, no mecônio e nas membranas fetais, originando, assim, a hipótese de que a troca maternofetal de bactérias ocorre antes do nascimento, por meio da placenta, semeando a microbiota intestinal do feto. ${ }^{16}$

O desenvolvimento inicial da microbiota infantil depende da transmissão de bactérias e metabólitos nos períodos pré-natal (cordão umbilical e líquido amniótico) e pós-natal (flora vaginal ao nascimento, amamentação, pele a pele e contato com o meio), e a microbiota evolui rapidamente no início da vida. ${ }^{17}$

Uma microbiota intestinal saudável é útil para o hospedeiro em muitos aspectos, incluindo o fornecimento de nutrientes, a proteção contra patógenos e a maturação das respostas imunológicas. A disbiose desempenha um papel importante em várias doenças na infância e na vida adulta e, entre elas, a obesidade é muito prevalente. ${ }^{4}$

Um estudo foi realizado onde se avaliaram 67 crianças com peso normal e 71 crianças obesas, com idades entre seis e 12 anos, no intuito de se comparar a composição da microbiota intestinal de crianças obesas àquela de crianças com

Rev. Port.Saúde e Sociedade.2019;4(1): 1028 - 1054. 
peso normal. ${ }^{18}$ Observou-se que existem espécies bacterianas associadas à obesidade, pois elas se correlacionaram positivamente com o percentual de gordura corporal. Esse estudo aponta que as crianças obesas apresentam uma microbiota bacteriana em estado de disbiose.

Os mecanismos pelos quais os antibióticos modulam o ganho de peso não são totalmente esclarecidos, mas várias hipóteses têm sido propostas, as quais incluem as seguintes: o aumento da capacidade das bactérias intestinais em extrair energia de polissacarídeos indigeríveis; a redução no número de bactérias que são metabolicamente protetivas contra a obesidade; a lipogênese hepática alterada; a sinalização metabólica alterada e a deficiência da defesa intestinal e da imunidade. ${ }^{19}$

A flora intestinal bacteriana de uma criança saudável possui bactérias capazes de decompor os polissacarídeos não digeridos (fibras) em ácidos graxos de cadeia curta, que fornecem 80-200 kcal por dia de energia. A disbiose (por exemplo, um aumento de $20 \%$ de Firmicutes e uma diminuição correspondente de $20 \%$ de Bifidobacterium) pode resultar em um adicional de $150 \mathrm{kcal}$ de energia colhida por dia. Os ácidos graxos de cadeia curta também modulam a secreção de hormônios intestinais (peptídeo semelhante ao glucagon [GLP-1] e peptídeo YY), sendo que ambos influenciam diretamente a sensação de saciedade. ${ }^{19}$

A sensibilidade que a microbiota intestinal, em processo de formação, possui aos antibióticos é percebida mesmo no período de vida intrauterina. A exposição pré-natal aos antibióticos pode desregular permanentemente os padrões metabólicos fetais. ${ }^{20}$

A perturbação da microbiota intestinal no período perinatal, causada pelo uso de antibióticos, parece programar o hospedeiro para um fenótipo metabólico propenso à obesidade, que persiste após os antibióticos terem sido descontinuados e a microbiota intestinal ter se recuperado do processo de disbiose. ${ }^{1}$

A exposição aos antibióticos, principalmente, os de amplo espectro, nas primeiras fases de desenvolvimento e crescimento do lactente, possui um efeito negativo sobre a microbiota intestinal, e é um fator responsável pela disbiose da flora bacteriana intestinal. A disbiose da microbiota intestinal, nos primeiros momentos de vida, é o ponto-chave para a gênese de desequilíbrios metabólicos que são fatores indutores da obesidade. ${ }^{21}$

Rev. Port.Saúde e Sociedade.2019;4(1): 1028 - 1054. 
Compreende-se, portanto, que a microbiota intestinal desempenha um papel relevante no condicionamento do peso corporal e que a disbiose da microbiota intestinal, relacionada ao uso de antibióticos, está associada ao sobrepeso e à obesidade no decorrer da vida do indivíduo. Foi observado, também, que a alteração da composição da microbiota persiste além do período de administração de antibióticos e leva ao surgimento de vários problemas, incluindo o sobrepeso e a obesidade tardia. Infelizmente, nem todos os mecanismos que poderiam explicar as relações entre a modificação da microbiota intestinal e o desenvolvimento da obesidade são definidos, mas já é claro que existe uma íntima relação entre a disbiose induzida por antibióticos no início da vida e o desenvolvimento da obesidade.

\section{Exposição aos antibióticos nas fases iniciais da vida e as suas relações com o sobrepeso e com a obesidade}

Um estudo longitudinal ${ }^{22}$ coletou dados, por meio de documentos médicos, de 257.729 crianças com idades entre dois e 18 anos, entre janeiro de 2001 e fevereiro de 2012. Após a aplicação dos critérios de inclusão, 163.820 crianças participaram da pesquisa. Foram avaliadas as associações das exposições aos antibióticos à trajetória do IMC durante toda a infância. Esse é um dos maiores estudos, até o momento, que analisam a relação entre os antibióticos e as trajetórias longitudinais do IMC em crianças. Em conclusão, percebe-se uma combinação de associações reversíveis, persistentes e progressivas em várias classes de antibióticos, mas todos eles apresentaram uma influência sobre a obesidade. Os resultados sugerem que o uso de antibióticos influencia o ganho de peso durante toda a infância e adolescência e não apenas durante os primeiros anos de vida.

Foi realizado um estudo de coorte retrospectivo com 21.714 crianças na Rede de Melhoramento da Saúde do Reino Unido, por meio de registros médicos eletrônicos, de 1995 a 2013. Na coorte, 1306 das crianças (6,4\%) tornaram-se obesas aos quatro anos de idade. A exposição aos antibióticos foi associada a um risco aumentado de obesidade nessa idade. A conclusão do estudo foi que a administração de três ou mais ciclos de antibióticos às crianças com menos de dois anos está associada a um risco aumentado de obesidade na primeira infância. ${ }^{15}$

Rev. Port.Saúde e Sociedade.2019;4(1): 1028 - 1054. 
Um trabalho realizado avaliou 436 díades mãe-filho, acompanhadas até os sete anos de idade, com dados completos. ${ }^{16}$ Foi identificado que as crianças nascidas de mães que tomaram antibióticos no segundo ou terceiro trimestre da gravidez tiveram um risco de obesidade $84 \%$ maior aos sete anos, em comparação a crianças cujas mães não relataram a exposição a antibióticos durante esse período.

Em um grande estudo realizadodurante o intervalo de 2001 a 2009, 89.057 crianças foram analisadas na rede de atenção primária do Children's Hospital of Philadelphia, uma grande rede de atenção primária pediátrica, cobrindo parte do leste dos Estados Unidos. ${ }^{23}$ A coorte incluiu 65.480 crianças. Os resultados sugerem que o uso de antibióticos de amplo espectro antes dos 24 meses de vida pode ser um fator favorável ao ganho excessivo de peso.

Com dados de prontuários eletrônicos de 64 mil crianças, ${ }^{24}$ identificaram uma associação entre o número de episódios de tratamento com antibióticos durante os primeiros dois anos de vida e o desenvolvimento de obesidade na infância, um efeito que foi mais pronunciado nos antibióticos de amplo espectro.

Uma revisão sistemática foi realizada no intuito de avaliar, de maneira abrangente, o impacto da exposição a antibióticos na adiposidade infantil. ${ }^{26}$ Uma pesquisa bibliográfica na MEDLINE, Embase e Web of Science foi realizada para encontrar artigos que examinaram o impacto da exposição aos antibióticos no risco de adiposidade infantil. A partir da pesquisa bibliográfica, encontrou-se um total de 1.294 resumos, mas apenas 26 estudos foram considerados como potencialmente elegíveis. Após a avaliação detalhada, 11 estudos foram escolhidos. Esta metanálise fornece fortes evidências para a relação entre a exposição aos antibióticos no início da vida e a adiposidade infantil. Há, também, uma relação dose-resposta óbvia entre a exposição aos antibióticos e a adiposidade infantil.

Depreende-se, dessa análise de dados, que o uso prudente de antibióticos é recomendado para gestantes, bebês e crianças, no intuito de se reduzir o risco do desenvolvimento da obesidade infantil.

\section{CONCLUSÃO}

Um estudo minucioso é recomendado para se iniciar qualquer pesquisa, seja ela original ou secundária, dos artigos disponíveis nas bases de dados das bibliotecas virtuais, a respeito do tema pretendido. Entretanto, o pesquisador

Rev. Port.Saúde e Sociedade.2019;4(1): 1028 - 1054. 
necessita da habilidade de manusear terminologias (descritores) para tornar a busca da informação científica efetiva. Na área da saúde, essas terminologias são conhecidas como Descritores em Ciências da Saúde e, para obter tais vocábulos estruturados, é preciso acessar o portal DeCS.

Neste estudo, foi obtido um levantamento de publicações científicas sobre a influência da exposição aos antibióticos, seja no período pré-natal ou no período pós-natal, no desenvolvimento da obesidade infantil. Os conteúdos dispostos nas três categorias desta pesquisa permitiram alcançar os objetivos estabelecidos.

Os portais MEDLINE, Biblioteca Virtual de Saúde (BVS), ScientificElectronic Library Online (SciELO), Literatura Latino-Americana e do Caribe em Ciências da Saúde (LILACS), Wiley Online Library e ScienceDirect tiveram uma participação crucial na construção das informações citadas e discutidas, sendo considerados ferramentas essenciais do objeto de estudo. De forma geral, esses portais atenderam às principais necessidades da pesquisa, contemplando textos científicos completos, em publicações de variados periódicos, sobre a influência dos antibióticos no desenvolvimento da obesidade infantil.

Quanto à crescente prevalência da obesidade infantil, é importante ressaltar que essa questão se tornou um grande desafio global para a saúde, e ações para reduzir a prevalência da obesidade em crianças e adolescentes são urgentemente necessárias. A investigação de fatores de risco associados à obesidade infantil pode ajudar a desenvolver intervenções preventivas eficazes. Esta revisão sistemática integrativa sugere que a exposição aos antibióticos pode resultar em um aumento do risco da obesidade infantil. A antibioticoterapia é capaz de mudar a microbiota intestinal para estados disbióticos, o que pode levar ao desenvolvimento e/ou ao agravamento da obesidade. Esse achado possui importantes implicações no cenário clínico, uma vez que os antibióticos estão entre os fármacos mais comuns administrados em lactentes e crianças.

Como a obesidade infantil é uma condição multifatorial, reduzir a prevalência depende da identificação e do gerenciamento de múltiplos fatores de risco, entre eles, a exposição precoce aos antibióticos. Promover o desenvolvimento natural da microbiota pode ser uma maneira eficaz de melhorar a saúde da criança em longo prazo.

Enfim, os profissionais médicos devem considerar a disbiose causada pelo uso de antibióticos nas fases iniciais da vida como uma nova e séria razão para o

Rev. Port.Saúde e Sociedade.2019;4(1): 1028 - 1054. 
uso criterioso de antibióticos na prática clínica, pois, de fato, é existente e comprovada a relação entre a antibioticoterapia e a obesidade infantil.

\section{REFERENCES}

1. Turta O, Rautava S. Antibiotics, obesity and the link to microbes - what are we doing to our children? BMC med. 2016; 14:1-6. Doi:https://doi.org/10.1186/s12916-016-0605-7

2. Lemas DJ, Yee S, Cacho N, Miller D, Cardel M, Gurka M, Janicke D, Shenkman E. Exploring the contribution of maternal antibiotics and breastfeeding to development of the infant microbiome and pediatric obesity. Semin Fetal Neonatal Med. 2016 Dec: 21(6):406-9. Doi: 10.1016/j.siny.2016.04.013

3. Vangay $P$, Ward T, Gerber JS, Knights D. Antibiotics, pediatric dysbiosis, and disease. Cell host microbe. 2015 May; 17(5):553-64.Doi: 10.1016/j.chom.2015.04.006.

4. Lu CY, Ni YH. Gut microbiota and the development of pediatric diseases. J Gastroenterol. 2015 July; 50(7):720-6.Doi: 10.1007/s00535-015-1082-z.

5. Korpela K, Salonen A, Virta LJ, Kekkonen RA, de Vos WM. Association of early-life antibiotic use and protective effects of breastfeeding: role of the intestinal microbiota. JAMA Pediatr. 2016 Aug;170(8):750-7. Doi: 10.1001/jamapediatrics.2016.0585.

6. Riva A, Borgo F, Lassandro C, Verduci E, Morace G, Borghi E, et al. Pediatric obesity is associated with an altered gut microbiota and discordant shifts in firmicutes populations. Environ microbiol. 2017 Jan; 19(1):95-105. Doi: $10.1111 / 1462-2920.13463$

7. Koleva PT, Bridgman SL, Kozyrskyj AL. The infant gut microbiome: evidence for obesity risk and dietary intervention. Nutrients. 2015 Mar ;7(4):2237-60.Doi: $10.3390 /$ nu 7042237

8. Emmanouil A, Raoult D. Gut microbiota modifications and weight gain in early life. HumanMicrobiomeJournal. $2018 \quad$ Apr; $\quad 7(8): 10-14$.Doi: https://doi.org/10.1016/j.humic.2018.01.002

9. van Best N, Hornef MW, Savelkoul PH, Penders J. On the Origin of Species: Factors Shaping the Establishment of Infant's Gut Microbiota. Birth defects res Part C Embryo Today. 2015 Dec;105(4):240-51.Doi: 10.1002/bdrc.21113

10. Botelho LLR, Cunha CCA, Macedo $M$. The integrative review method in organizationalstudies. Gestão Soc. 2011 May/Aug; 5(11):121-36. Doi: https://doi.org/10.21171/ges.v5i11.1220

11. Schmoeller R, Trindade LL, Neis MB, Gelbcke FL, Pires DEP. Nursingworkloadsandworkingconditions: integrative review. Rev Gaúcha Enferm. 2011 June; 32(2):368-77. Doi:http://dx.doi.org/10.1590/S198314472011000200022

12. Melnyk BM, Fineout-Overholt E. Making the case for evidence-based practice. In: Melnyk BM, Fineout-Overholt E. Evidence-based practice in nursing \& healthcare: A guide to best practice. Philadelphia: Lippincot Williams \& Wilkins; 2005. p.3-24.

Rev. Port.Saúde e Sociedade.2019;4(1): 1028 - 1054. 
13. García-MantranaI, Bertua B, Martínez-Costa C, Collado MC. Perinatal nutrition: how to take care of the gut microbiota? ClinNutr Exp. 2016 Apr; 6:3-16. Doi:https://doi.org/10.1016/j.yclnex.2016.02.002

14. Moscetti CW, Pronk NP. Invisible seams: preventing childhood obesity through an improved obstetrics-pediatrics care continuum. PrevMed Rep. 2016 Nov; 5:1-3.Doi: 10.1016/j.pmedr.2016.11.006

15. Scott FI, Horton DB, Mamtani R, Haynes K, Goldberg DS, Lee DY, et al. Administration of antibiotics to children before age 2 years increases risk for childhood obesity. Gastroenterol. 2016 July; 151(1):120-9.Doi: 10.1053/j.gastro.2016.03.006

16. Mueller NT, Whyatt R, Hoepner L, Oberfield S, Dominguez-Bello MG, Widen EM, et al. Prenatal exposure to antibiotics, cesarean section and risk of childhood obesity. Int J Obes (Lond). 2015 Apr; 39(4):665-70.Doi: 10.1038/ijo.2014.180

17. Yallapragada SG, Nash CB, Robinson DT. Early-life exposure to antibiotics, alterations in the intestinal microbiome, and risk of metabolic disease in children and adults. Pediatr. 2015 Nov; 44(11):e265-9.Doi: 10.3928/00904481-20151112-09

18. Lopez-Contreras BE, Moran-Ramos S, Villarruel-Vazquez R, Macias-Kauffer $L$, Villamil-Ramirez $\mathrm{H}$, Leon-Mimila $\mathrm{P}$, et al. Composition of gut microbiota in obese and normal-weight Mexican school-age children and its association with metabolic traits. Pediatrobes. 2018 June; 13(6):381-8.Doi: 10.1111/ijpo.12262

19. Leong KSW, Derraik JGB, Hofman PL, Cutfield WS. Antibiotics, gut microbiome and obesity. Clinendocrinol. 2018 Feb;88(2):185-200.Doi: 10.1111/cen.13495

20. Mor A, Antonsen S, Kahlert J, Holsteen V, Jorgensen S, Holm-Pedersen, et al. Prenatal exposure to systemic antibacterials and overweight and obesity in Danish schoolchildren: a prevalence study. Int J Obes (Lond). 2015 Oct; 39(10):14505.Doi: $10.1038 /$ ijo.2015.129

21. Magsarili HK, Girotto JE, Bennett NJ, Nicolau DP. Making a case for pediatric antimicrobial stewardship programs. Pharmacotherapy. 2015 Nov; 35:102636. Doi: $10.1002 /$ phar.1647

22. Schwartz BS, Pollak J, Bailey-Davis L, Hirsch AG, Cosgrove SE, Nau C, et al. Antibiotic use and childhood body mass index trajectory. Int J Obes. 2016 Apr; 40(4):615-21.Doi: 10.1038/ijo.2015.218Doi: 10.1038/ijo.2015.218

23. Bailey LC, Forrest CB, Zhang P, Richards TM, Livshits A, DeRusso PA.Association of antibiotics in infancy with early childhood obesity. JAMA Pediatr. 2014 Nov; 168(11):1063-9.Doi: 10.1001/jamapediatrics.2014.1539

24. Forrest CB, Block JP, Bailey LC. Antibiotics, infections, and childhood obesity. Lancet Diabetes Endocrinol. 2017 Jan; 5(1):2-3.Doi: 10.1016/S22138587(16)30314-X.

25. Shao X, Ding X, Wang B, Li L, An X, Yao Q, et al. Antibiotic exposure in early life increases risk of childhood obesity: a systematic review and meta-analysis. Front Endocrinol. 2017; 8:170.Doi: 10.3389/fendo.2017.00170.

Rev. Port.Saúde e Sociedade.2019;4(1): 1028 - 1054. 